\title{
Questes
}

vestes Revue pluridisciplinaire d'études médiévales

\section{Culture de l'autre : introduction}

\section{Viviane Griveau-Genest et Pauline Guena}

\section{OpenEdition}

Journals

Édition électronique

URL : http://journals.openedition.org/questes/4389

DOI : 10.4000/questes.4389

ISSN : 2109-9472

\section{Éditeur}

Les Amis de Questes

\section{Édition imprimée}

Date de publication : 31 mars 2017

Pagination : 13-32

ISSN : 2102-7188

\section{Référence électronique}

Viviane Griveau-Genest et Pauline Guena, «Culture de l'autre : introduction », Questes [En ligne],

35 | 2017, mis en ligne le 15 avril 2017, consulté le 01 mai 2019. URL : http://journals.openedition.org/ questes/4389; DOI : 10.4000/questes.4389 


\title{
Introduction
}

\section{Viviane GriveAu-Genest et Pauline GuENA}

\author{
Université Paris-Ouest Nanterre et Université Paris-Sorbonne
}

S'interroger sur les cultures de l'autre au Moyen Âge, c'est s'engager sur une route relativement bien balisée ${ }^{1}$. L'autre et la culture : voilà deux concepts dont les sciences sociales sont désormais férues, et qui, lorsqu'ils sont conjugués, amènent fréquemment à poser la question de l'identité. L'autre servirait alors de miroir, permettant de refléter la nature même de celui qui lui est confronté. Dans la rencontre entre deux textes, deux individus, deux groupes, se jouerait à la fois la question de l'altérité, et celle de la nature même de chaque groupe, sauf si l'on considère immédiatement que la culture n'a rien de naturel, qu'elle n'est pas un isolat qui précèderait la fameuse rencontre avec l'autre, mais

1 Le sujet bénéficie d'ailleurs depuis 1995 d'une revue propre: Medieval encounters, Jewish, Christian, Muslims in confluence and dialogue, Leiden, Brill. Plusieurs synthèses ont également été esquissées depuis ces mêmes années: Jerry H. Bentley, Old world encounters : cross-cultural contacts and exchanges in pre-modern times, New York, Oxford University Press, 1993. Répondant à la formule de Stephen Greenblatt qui avait évoqué le paradigme des « New World Encounters », Jeremy Bentley insistait d'abord sur les conditions des rencontres qualifiées de «cross-cultural ». Plus récemment, Richard Gyug a croisé cette approche avec les acquis de la littérature comparée, tout en s'interrogeant sur la façon d'enseigner ces thèmes : Richard Gyug, Medieval cultures in contact, New York, Fordham University Press, coll. "Fordham series in medieval studies», 2003. Le souci pédagogique donne désormais lieu à d'autres publications anglo-saxonnes : Karina F. Attar et Lynn Shutters, Teaching medieval and early modern cross-cultural encounters, New York, Palgrave Macmillan, coll. « The new Middle Ages », 2014. 
qu'elle se définit en permanence dans ces croisements avec des altérités elles-mêmes construites comme telles² .

Le syntagme «culture de l'autre » interroge le chercheur au seuil de son étude, car les termes qu'il mobilise ne sont pas usités au Moyen Âge : ils lui sont «étrangers ». En effet, un détour par le lexique montre qu'aultre est d'abord un adjectif ou un pronom intégré au sein d'un système de comparaison. Cette acception demeure longtemps la norme puisque c'est elle que recense le Littré. L'autre substantivé, et son corollaire, l'altérité, qui met en lumière ce qui rend différent, n'interviennent donc qu'au cours du $\mathrm{XX}^{\mathrm{e}}$ siècle, à la faveur des pensées des «maîtres du soupçon ${ }^{3} »$.

Pourtant, nous savons bien que l'Occident médiéval ne méconnaît ni l'altérité ni la confrontation des cultures. Les discours et les textes, à commencer par les sources théologiques et littéraires, thématisent fortement la différence, qu'elle soit religieuse ou plus largement

2 Rogers Brubaker, Ethnicity without groups, Cambridge, Mass., Harvard University Press, 2004. Voir notamment la section intitulée "groupness as an event », p. 11-18.

3 L'expression est de Paul Ricœur: voir «Démythiser l'accusation», dans Démythisation et morale, dir. Enrico Castelli, Paris, Aubier-Éditions Montaigne, 1965, p. 49-77 ; elle s'applique à l'origine à Freud, Marx et Nietzsche. Le tournant $\mathrm{du} \mathrm{XIX}^{\mathrm{e}}-\mathrm{XX}^{\mathrm{e}}$ siècle introduit en effet une rupture importante dans le paradigme de la connaissance, marquée jusqu'alors par le primat d'un rationalisme positiviste dans les méthodes. Les travaux de Freud, du côté de la psyché humaine, de Marx, pour les phénomènes socio-politiques, de Nietzsche sur le discours moral, ou encore de Max Weber, pour les structures sociales de la religion, introduisent tous un soupçon à l'égard de la réalité apparente et des discours qui s'y rattachent. Dans cette perspective, la vérité est à chercher non pas à la surface, mais en-deçà et suivant une herméneutique qui récuse l'évidence ainsi qu'une méthodologie formaliste. C'est à la faveur de l'éclosion du structuralisme dans la deuxième moitié du $\mathrm{Xx}^{\mathrm{e}}$ siècle que les sciences humaines vont faire leur ces théories et ces approches. L'intérêt pour la place de l'altérité ou l'étrangeté dans la culture médiévale ressort principalement à ces herméneutiques qui s'efforcent de déconstruire les discours apparents pour mettre au jour des significations secondes. Sur cette question, on lira en guise d'introduction Jean-Charles Huchet, Littérature médiévale et psychanalyse. Pour une clinique littéraire, Paris, PUF, 1990. 
culturelle $^{4}$ : au chrétien s'opposent... tous les autres, rassemblés commodément sous le vocable païens. Certains d'entre eux sont parfois désignés expressément dans leur différence : juifs, sarrasins ou encore hérétiques ${ }^{5}$. L'altérité peut en outre avoir trait à l'origine géographique et le lexique s'en fait l'écho: Bretons, Flamands, Picards, Anglais, etc., dessinent la trame culturelle des médiévaux, jusqu'à l'échelle la plus ténue. Dans une société communautaire, les affiliations se superposent, décuplant à l'infini ces « autres » culturels.

Un dernier paradigme lexical, absent de notre titre, vient éclairer le binôme moderne autrelaltérité : il s'agit d'estranger/estrange. En effet, l'estranger est bien identifié sur des critères culturels : $\operatorname{Renard}^{6}$ en a conscience, quand il joue d'un grimage physique, une peinture jaune, et d'un grimage linguistique, un patois anglais, pour leurrer Ysengrin. Par ailleurs, le sémantisme du terme estrange, fortement thématisé par les textes merveilleux, souligne que toute différence ouvre sur un espace symbolique où elle est relue à la lumière du fantasme et de sentiments ambivalents : peur, admiration, rejet, fascination. Faut-il voir dans les créatures merveilleuses de la matière de Bretagne des figurations d'une relation à une altérité culturelle, à la suite des travaux de Sharon Kinoshita $^{7}$ et Sylviat Huot portant sur Marie de France et le Roman de

${ }^{4}$ Voir, à titre d'exemple dans la littérature romanesque, l'ouvrage Cultural Encounters in the Romance of Medieval England, dir. Corinne Saunders, Cambridge, D. S. Brewer, 2005.

${ }^{5}$ Sur le rapport d'exclusion sur lequel se constitue en partie la pensée sociale médiévale, on relira l'ouvrage de Dominique Iogna-Prat, Ordonner et exclure, Paris, Aubier, 1998, p. 367. Pour l'auteur, cette mise à l'écart ne vaut pas seulement pour des communautés religieuses (juifs, musulmans), mais aussi pour des groupes fondés sur d'autres critères, notamment les femmes.

${ }^{6}$ Voir Le Roman de renart, Première branche [1997], éd. Mario Roques, Paris, Honoré Champion, 2007, p. 80-81.

${ }^{7}$ L'approche de la littérature romane à la lumière de l'angle culturel a connu un certain succès et on se reportera, en guise d'entrée en matière, aux travaux de Sharon Kinoshita, Medieval boundaries: Rethinking difference in old french littérature, Philadelphia, University of Pennsylvania Press, 2006, ainsi qu'à l'article de 
Perceforest ? La question mérite ainsi d'être posée, car les métaphores des textes et les métaphores des chercheurs ne relèvent pas toujours du même univers mental ${ }^{8}$.

\section{Rencontres multiples, unité de lieu, unité de temps}

Les métaphores proposées par les chercheurs pour pointer les croisements incessants entre les genres, les œuvres, les hommes, ou les groupes sociaux ont beaucoup emprunté aux sciences dures. Serge Gruzinski parlait de la «pensée métisse », terme qui érigeait la culture en lieu de croisement par excellence, enrichi par l'apport d'autres systèmes de pensée 9 . Jean Loup Amselle, anthropologue et africaniste, affirmait aller plus loin en substituant à l'idée de «métissage» celle de «branchements »: pour lui, pas d'isolat préalable à la rencontre, pas de système qui pourrait être clos sur lui-même, toute culture était en mouvement continu, construite à travers les branchements qu'elle se proposait ${ }^{10}$. L'historien et l'anthropologue partageaient le même refus : celui de parler de multiculturalisme en envisageant des sociétés ou des

Voichita-Maria Sasu, «Dépaysement et exotisme dans le roman d'aventures français ", dans Les Représentations de l'autre du Moyen Âge au XVII siècle : mélanges en l'honneur de Kazimierz Kupisz, dir. Évelyne Berriot-Salvadore, SaintÉtienne, publications de l'Université de Saint-Étienne, 1995, p. 65-72.

${ }^{8}$ Nous y reviendrons, mais on pourra d'ores et déjà consulter, pour un point de vue nuancé sur les métaphores heuristiques des courants actuels de la recherche, l'article de Marion Uhlig, "Quand "Postcolonial" et "Global" riment avec "Médiéval" : sur quelques approches théoriques anglo-saxonnes », Perspectives Médiévales, $\mathrm{n}^{\mathrm{0}} 35$, 2014, consulté le 05 juillet 2016.

${ }^{9}$ Serge Gruzinski, La Pensée métisse, Paris, Fayard, coll. «Pluriel », 1999.

10 Jean-Loup Amselle, Branchements: anthropologie de l'universalité des cultures, Paris, Flammarion, coll. «Champs. Essais», 2001. On pourra également, dans une perspective plus large, s'intéresser à la fortune du concept de «rhizome », forgé par Gilles Deleuze et Félix Guattari, qui rencontre un écho tout à fait favorable dans le domaine des études postcoloniales: Gilles Deleuze et Félix Guattari, Rhizome, Paris, Éditions de Minuit, 1976 ; ainsi que Bill Ashcroft, Gareth Griffiths et Helen Tiffin, Post-colonial studies. The Key concepts [2000], London/New York, Routledge, 2008. 
productions culturelles faites d'addition. À ces additions étaient préférées différentes métaphores pointant vers des pratiques syncrétiques. Quelle réalité ont ces concepts pour l'histoire et pour la littérature médiévale ?

La recherche sur la littérature médiévale s'est intéressée depuis longtemps à la question de l'altérité en un sens esthétique : la tradition critique a d'abord traité le motif de la rencontre de l'autre à travers les figures de la fée et de son double, l'homme sauvage dans la matière de Bretagne $^{11}$. Certes, ces expériences qu'on trouve chez Marie de France, Chrétien de Troyes ou Jean d'Arras questionnent la culture et les limites de l'humain. Pourtant, l'accent porte d'abord sur le binôme culture/sauvagerie $^{12}$ : l'intérêt ne va pas à la rencontre d'une culture appréhendée comme telle, quoiqu'autre. En réalité, passé le texte fondateur en la matière de la Chanson de Roland ${ }^{13}$, c'est d'abord par le détour de l'Antiquité que le Moyen Âge s'est posé la question de l'altérité culturelle. Les études sur la matière de Rome ${ }^{14}$, initiées entre autres par Francine Mora Lebrun, Aimé Petit et Emmanuèle Baumgartner ont ainsi montré que la thématique antiquisante-orientale était déjà un questionnement croisant altérité culturelle et filiation originaire. Plus

${ }^{11}$ Pour une synthèse et une première entrée bibliographique, on se reportera à l'ouvrage récent et résumant les grands apports de ce courant de recherche de Laurence Harf-Lancner, Le Monde des fées dans l'Occident médiéval, Paris, Hachette, 2003.

${ }^{12}$ Sur la perception et l'imaginaire de la forêt, voir Jacques Le Goff, « Le désert forêt dans l'Occident médiéval », dans L'imaginaire médiéval, Paris, Gallimard, 1985, p. 59-75.

${ }^{13}$ Pour une approche culturelle de la Chanson de Roland, on se reportera à Simon Gaunt, "The Chanson de Roland and the invention of France », dans Rethinking Heritage: Cultures and Politics in Europe, dir. Robert Shannan Peckham, London/New York, Tauris, 2003, p. 90-101, ainsi qu'à Jean-Charles Payen, «L'hégémonie normande dans la Chanson de Roland et les Gesta Tancredi: de la Neustrie à la chrétienté, ou Turold est-il nationaliste ? », dans Romance Epic : Essays on a Medieval Literary Genre, dir. Hans-Erich Keller, Kalamazoo, Medieval Institute Publications, 1987, p. 73-90, pour une approche détaillée de l'idéologie des textes.

${ }^{14}$ Pour une introduction à la matière dite « antique », on se reportera à l'ouvrage collectif dirigé par Laurence Harf-Lancner, Laurence Mathey-Maille et Michelle Szkilnik, Conter de Troie et d'Alexandre, Paris, Presses Sorbonne Nouvelle, 2006. 
marginaux, les récits de voyage et de pèlerinage ont aussi ouvert la voie à des études sur les rencontres dont ils sont le théâtre ${ }^{15}$. Il en ressort que la rencontre avec l'autre se déploie sur une échelle graduée, depuis la caricature, qui sert uniquement le cheminement spirituel du je autobiographique du pèlerin-narrateur, à la rencontre réelle. C'est le cas dans l'Evagatorium, récit de pèlerinage en Orient $\mathrm{du} \mathrm{XV}^{\mathrm{e}}$ siècle, où le dominicain Félix Fabri omet la différence culturelle chez ceux qu'il rencontre pour ne voir en eux que des frères humains ${ }^{16}$.

Plus récemment, la question de la culture de l'autre a été reprise non plus comme thème ou motif littéraire, objets de l'écriture, mais comme grille de lecture extérieure mettant au jour des dynamiques du texte. Les seiziémistes, par l'étude des grandes découvertes, ont à cet égard offert des outils intéressants pour revenir sur la question du sauvage dans sa dimension culturelle, ouvrant ainsi la voie à une réflexion sur un Occident décentré ${ }^{17}$. Les approches inspirées des post

15 Voir Aryeh Graboïs, Le Pèlerin occidental en Terre sainte au Moyen Âge, Bruxelles, De Boeck, 1998 et Marie-Christine Gomez-Géraud, Le Crépuscule du grand voyage. Les récits de pèlerins à Jérusalem, Paris, Champion, 1999.

${ }^{16}$ Sur cette rencontre littéraire forte, et sur son corollaire, le goût pour les monstres naturels de l'Orient, voir Jean Meyers, «Merveilleux et fantastique dans le récit de voyage », dans «Furent les merveilles pruvees et les aventures truvees », dir. Francis Gingras, François Laurent, Frédérique Le Nan et Jean-René Valette, Paris, Honoré Champion, 2005, p. 437-463 : «Chez Frère Félix, qui pleure dans les bras de son ânier Galelacassa au moment de le quitter, l'autre, l'ailleurs et l'autrefois ne sont jamais si éloignés qu'on ne puisse les rapprocher de soi : l'altérité pour lui n'est souvent qu'une autre face de soi-même », p. 463.

17 Voir Frédéric Tinguely, La Renaissance décentrée, Genève, Librairie Droz, 2008. C'est également en histoire, le propos de Thomas Tanasse dans son étude des missions franciscaines auprès du grand Khan : il y défend une approche historiographique qui dépasse le seul référentiel occidental pour appréhender l'Europe de l'ouest comme une zone à l'écart des grandes routes commerciales par lesquelles circulent les innovations techniques et les richesses depuis l'extrême orient jusqu'en Asie centrale. Voir Thomas Tanasse, "Jusqu'aux limites du monde ». La Papauté et la mission franciscaine de l'Asie de Marco Polo à l'Amérique de Christophe Colomb, Rome, École Française de Rome, 2013. 
colonial studies ${ }^{18}$ ont en outre nourri des travaux nouveaux sur la base des ressemblances existant entre le Moyen Âge, peu centralisé, et notre monde globalisé. La pertinence des concepts ainsi mobilisés doit être questionnée, ainsi que le rappellent Marion Uligh et Simon Gaunt, car leur caractère séduisant tient autant à leur fécondité heuristique qu'aux échos implicites qu'ils font à notre propre époque ${ }^{19}$. C'est là pourtant un dilemme ancien pour le médiéviste, ainsi que Paul Zumthor l'avait rappelé dans Parler du Moyen Âge $e^{20}$ : nos lectures n'échappent ni à notre subjectivité, ni, ce faisant, à l'anachronisme.

La rencontre est alors au cœur de toutes les attentions : elle est le moment où se nouent les circulations matérielles, humaines et intellectuelles qui montrent la fluidité des cultures. Elle souligne aussi que le monde contemporain globalisé, connecté, métisse, n'est pas une invention du XIX ${ }^{\mathrm{e}}$ siècle, ni même de la Renaissance ${ }^{21}$. Comme dans tout champ qui se constitue et s'autonomise, la rencontre a désormais ses héros : des héros littéraires tels que les traducteurs, des héros historiques tels que les marchands ou les diplomates. On évoque les hauts faits des grands voyageurs: Erik le Rouge, Marco Polo ou Ibn Khaldun. On invoque les hauts lieux des échanges culturels : Bagdad, la péninsule ibérique, Venise, Constantinople. Certains groupes identifiés religieusement ou économiquement sont érigés en passeurs : les juifs de

${ }^{18}$ On consultera, pour un premier aperçu de ces grilles de lecture, l'ouvrage de Sylvia Huot, Postcolonial fictions in the Roman de Perceforest, cultural identities and hybridities, Woodbridge/Rochester, D. S. Brewer, 2007.

19 L'actualité du Moyen Âge et son lien à l'époque contemporaine constitue un domaine important et florissant des études médiévales, comme le montre l'article de Michèle Gally et Vincent Ferré, «Médiévistes et modernistes face au médiéval », Perspectives médiévales, $\mathrm{n}^{\mathrm{o}} 35$, 2014, consulté le 06 juillet 2016. URL: http://peme.revues.org/5761.

20 Voir Paul Zumthor, Parler du Moyen Âge, Paris, Éditions de minuit, 1980, p. $29 s q$.

${ }^{21}$ Patrick Boucheron, Julien Loiseau, Pierre Monnet et Yann Potin, Histoire $d u$ monde au XV $V^{e}$ siècle, Paris, Fayard, coll « Pluriel », 2009. 
la Genizah ${ }^{22}$, les Karimis en Mer Rouge ${ }^{23}$. Pourtant, tout personnage qui circule peut-il être qualifié de passeur culturel ? Toute rencontre est-elle gage de dialogue et de paix ? Le roman du métissage ${ }^{24}$, gagne à ne pas être décontextualisé ou irénique. Dans cette perspective, le Moyen Âge réclame une attention particulière. Période longue, moins riche en sources, elle est facilement investie par différents mythes des origines consistant à rechercher l'état premier d'une culture, par exemple avant le «grand désenclavement du monde ${ }^{25}$ ». D'où l'importance d'étudier les rencontres, et de se pencher sur leur contexte : le contexte au sein d'une œuvre, le contexte d'écriture, ou même le contexte social. Ces rencontres s'incarnent dans des mots, des gestes, des écrits.

\section{Pourquoi rejeter, comment échanger?}

Dans la rencontre de la culture de l'autre, les livres et les textes peuvent d'abord être le moyen de l'échange au titre d'artefact culturel. Objet de prestige, ils peuvent s'inscrire dès lors dans une logique de don et contre-don où ils apportent une culture autre et/ou démontrent une supériorité culturelle. Le livre est à la fois objet diplomatique et médiateur culturel. Ainsi, dès le XII ${ }^{\mathrm{e}}$ siècle les textes traduits de l'arabe fournissent une voie d'accès à la pensée aristotélicienne. Plus tard, Brunet Latin, italien exilé en France du fait de conflits politiques, transmet en français dans le Livre du Trésor la rhétorique italienne.

${ }^{22}$ Shelomoh Dov Goitein a pourtant invalidé la thèse qui consistait à faire de la population juive du sultanat fatimide le cœur d'une "diaspora commerciale ». Shelomoh Dov Goitein, A Mediterranean society. The Jewish communities of the Arab world as portrayed in the documents of the Cairo Geniza. 2, Berkeley/Los Angeles, University of California Press, 1971.

23 Janet Lippman Abu-Lughod, Before European hegemony : the world system a.d. 1250-1350, New York, Oxford University Press, 1991, p. 227.

${ }^{24}$ Notons la constitution progressive d'un genre littéraire théorisé récemment par Denise Coussy, Cent romans-monde, Paris, Karthala, 2013.

${ }^{25}$ Nous renvoyons au Bulletin de Questes «Finir le Moyen Âge », Bulletin, n 33. 
Enfin, au seuil de la modernité, Pétrarque, en possession d'exemplaires grecs des textes d'Homère déplorera ne pouvoir les lire : les livres sont en effet des médiateurs partiels de la culture de l'autre et ils ne permettent qu'imparfaitement la rencontre, dès lors que les autres paramètres de l'extranéité, telle la langue, ne sont pas levés lors de la mise en contact. Ces rencontres manquées comptent pourtant: si, au début du $\mathrm{XV}^{\mathrm{e}}$ siècle, Nicolas de Clamanges ${ }^{26}$, chef de file du préhumanisme français, copie dans ses textes autographes le grec sans vraiment le comprendre, il pose ce faisant les bases du renouveau de l'enseignement du grec en France. Au-delà de la traduction, la matérialité des textes eux-mêmes permet également tous les métissages, du plurilinguisme à la diglossie et ses effets de code switching ${ }^{27}$. On pourra ici convoquer les notions modernes de créolisation et de diaspora en rappelant malicieusement qu'au cœur de la guerre de Cent Ans le français d'Angleterre reste une langue bien vivante et moins étrangère qu'il n'y paraît.

Les livres ne se limitent pas à l'humble statut d'objet échangé ou de trace d'une rencontre éphémère entre deux aires culturelles. Dans cette civilisation livresque qu'a élaborée l'Occident médiéval, ils sont tout autant des espaces où se joue la rencontre. La réécriture tente de dépasser l'altérité par l'omission, la déformation, mais aussi l'acclimatation. Les textes revêtent la dimension ambiguë de la frontière spatiale : genres et motifs y sont en effet une interface permettant la communication. Ainsi

${ }^{26}$ Gilbert Ouy, «In Search of the Earliest Traces of French Humanism : the Evidence from Codicology », The Library Chronicle, vol. XLIII, $\mathrm{n}^{\circ}$ 1, 1978, p. 3-38.

${ }^{27}$ Pour une approche linguistique de ces questions à partir de l'espace francophone médiéval, on consultera l'ouvrage collectif Medieval multilingualism. The francophone world and its neighbours, dir. Christopher Kleinhenz et Keith Busby, Turnhout, Brépols, 2010. La question de l'usage de la langue française en Angleterre y est traitée avec finesse. Sur le concept de code-switching, se reporter à l'ouvrage de référence: Dictionnaire d'Analyse du Discours, dir. Patrick Charaudeau et Dominique Maingueneau, Paris, Éditions du Seuil, 2002. 
l'écriture fabulistique du lai développée en langue romane par Marie de France se voit relue avec fécondité par Berekiah Hanaqdan dans la tradition moraliste hébraïque ${ }^{28}$. Dans le même temps, textes, genres et motifs son également les marqueurs distinctifs qui scellent la différence d'une culture à l'autre. Ainsi le passage du récit arabe de Kalîla et Dimna, fait de contes sapientiaux enchâssés mettant en scène des héros animaux, à la Disciplina Clericalis de Pierre Alphonse, texte didactique latin, est révélateur : les récits enchâssés à l'herméneutique riche cèdent la place à l'auctoritas et les animaux au couple maître/disciple ${ }^{29}$. Rencontre, échange, rejet : c'est ainsi l'acclimatation qui prime dans le texte du Heliand récit de la vie du Christ écrit à Fulda pour transmettre la vraie foi aux peuples germaniques, quand le caveau du défunt Lazare des Évangiles est transformé en une tombe creusée dans le sol et recouverte d'une roche, ce qui en fait un exemple typique des pratiques funéraires germaniques :

[le Christ] dit alors aux femmes de le mener là où Lazare était enseveli dans le sol. Il y avait là sur la tombe une pierre, un couvercle en roche dure.

\footnotetext{
${ }^{28}$ Sur ce corpus textuel, on renverra aux travaux de Tovi Bibring, entres autres «Le chemin corrigé : moralités inédites dans la fable La souris et la grenouille de Marie de France et Rat avec Rainette et Aigle de Berekiah Hanaqdan » dans Le Récit exemplaire (1200-1800), dir. Véronique Duché et Madeleine Jeay, Paris, Classiques Garnier, 2011, p. 37-58. Voir également, pour un aperçu de la circulation des récits au sein de l'espace interculturel qu'est la Romania, Medioevo Romanzo, vol. 30, $\mathrm{n}^{\mathrm{o}} 11$, 2006, Incontro di culture, la narrativa breve nella romània medievale, dir. Rosanna Brusegan et María Jesús Lacarra.

${ }^{29}$ Voir, sur cet exemple, Aboubakr Chraïbi, « De Kalîla et Dimna à la Disciplina Clericalis ou de Borzouyeh à Pierre Alphonse », dans D'Orient en Occident, Les recueils de fables enchâssés avant les Mille et une nuits de Galland, dir. Marion Uhlig et Yasmina Foehr-Janssens, Turnhout, Brépols, 2014, p. 41-77. Précisons que la version arabe de ce récit est elle-même le résultat d'une traduction depuis le pehlevi, réalisée dans un contexte de renforcement de la domination omeyyade et d'arabisation des élites persanes. Benoît Grévin, Le parchemin des cieux : essai sur le Moyen Âge du langage, Paris, Éd. du Seuil, coll. «L'Univers historique », 2012.
} 
Alors le Christ Saint ordonna de déplacer la pierre, en sorte qu'il puisse voir le corps et contempler le cadavre ${ }^{30}$.

La modification est fidélité : il s'agit de rendre accessible le message biblique. Qu'en est-il quand la rencontre des cultures passe par l'héritage ? Dans les textes, mais aussi dans l'iconographie, le legs de l'Antiquité au Moyen Âge pose en effet problème aux clercs chrétiens et le paganisme se voit souvent mis à la mode du dogme chrétien : ainsi les enfers virgiliens dans le Roman d'Énéas (v. 2839-2844 ; 2856-2859) ${ }^{31}$. Faut-il alors parler d'hybridation des cultures ou plutôt, en écho à l'image des nains sur les épaules de géants, doit-on parler d'une réappropriation réussie? Dans l'Enéas, la source est en effet assumée puisqu'elle est citée. L'intertextualité est souvent plus sinueuse et reste discrète sur la circulation des textes. C'est le cas par exemple du Roman des Sept Sages, qui transpose le Livre de Sindibad: le remaniement vigoureux du texte en un sens latin, chrétien et clérical est incontestable. Les conditions d'accès de son auteur, Jean de Haute-Seille, avec la matrice orientale demeurent quant à elles, mystérieuses.

Y a-t-il des métissages réussis en littérature, et quelle forme prendraient-ils: intégration consciente d'une différence assumée ou assimilation d'une différence que l'on souhaite plus ou moins oublier? Le destin migratoire couronné de succès du personnage du lion dans le Roman de Renart, le roi Noble offre une illustration parlante. Michel

${ }^{30}$ Heliand, L’Évangile de la Mer du Nord, éd. Éric Vanneufville, Turnhout, Brépols, 2008, p. 311-313.

${ }^{31}$ Le Roman d'Enéas, éd. Aimé Petit, Paris, Le Livre de Poche, 1997, p. 206-208. Texte : «Illuec a .I. feu parmanable /Nen ist lumiere ne clartez, /Il art et brulle les dampnez /Il les obscure et tormente, /Ne de repos n'ont cil atente [...] /Illuec vit mors et fins commence, /Definement y a cressence, /Destructïons, restoremens : /N'i faut paors por nulz tormenz. » 
Pastoureau $^{32}$ l'a rappelé, l'animal, inconnu des contrées européennes, vient à point nommé remplacer un ours par trop païen... Mais c'est également le cas de la figure d'Alexandre le $\mathrm{Grand}^{33}$ dont la légende, tour à tour noire ou blanche, voit subsister une part d'ambiguïté. En somme, en littérature, la rencontre est, comme ailleurs, régie par des logiques pragmatiques: souvent, n'est intégré que ce qui est utile et potentiellement signifiant dans la culture d'accueil.

De ce souci de ne pas enjoliver ou substantialiser les rencontres découlent deux questions subsidiaires : celle de l'échange et du rejet. Qu'est-ce qui est vraiment transmis lors d'une rencontre ? Qu'est-ce qui passe, et également qu'est-ce qui ne passe pas ? Quels mots, quels gestes, quels objets circulent d'une personne à l'autre ou d'un groupe à l'autre ? Plusieurs études ont insisté sur le fait qu'un objet pouvait changer de valeur ou même de fonction en passant d'une aire culturelle à l'autre. En faisant d'objets matériels le sujet d'études qui les suivent dans leur parcours, le but est finalement d'insister sur le rôle essentiel du contexte, et d'affirmer que les sociétés ne sont pas passives face aux objets, qu'elles ont la capacité de se les approprier ${ }^{34}$. L'échange n'est donc jamais une communication sans filtre.

\footnotetext{
${ }^{32}$ Michel Pastoureau, L'Ours. Histoire d'un roi déchu, Paris, Éditions du Seuil, 2007, p. 181-187 et 216-219.

33 Alexandre le Grand dans les littératures occidentales et proche-orientales, éd. Laurence Harf-Lancner, Claude-Claire Kappler et François Suard, Nanterre, Centre des Sciences de la littérature, Hors-série de la revue Littérales, 1999.

${ }^{34}$ Ce champ avait été ouvert par l'anthropologie. Voir par exemple l'importance du contexte d'échange des objets mis en valeur par Arjun Appadurai, The social life of things: commodities in cultural perspective, New York, Cambridge University Press, coll «Cambridge Studies in Social and Cultural Anthropology », 1986. Il se développe ensuite en histoire: Nicholas Thomas, Entangled objects : exchange, material culture, and colonialism in the Pacific, London, Harvard University Press, coll. «The contemporary Pacific», 1991. Le Moyen Âge reprend désormais ces thématiques, voir Valentin Groebner, Liquid assets, dangerous gifts : presents and politics at the end of the Middle Ages, Philadelphia, University of Pennsylvania Press, coll. "The Middle Ages series », 2002 ; et plus proche de notre sujet : The Power of things and the flow of cultural transformations : art and culture between Europe and
} 
Un autre aspect se dégage également, celui du rejet. Envisager la possibilité d'une rencontre valorisée, acceptée, fructueuse en termes d'échanges, c'est concevoir aussi qu'une rencontre puisse parfois échouer. En ce sens, on peut se demander quelles sont les modalités d'un contact réussi, et à quelles conditions certains individus ou certains groupes font une place à l'autre et à sa culture ${ }^{35}$. Les hauts-lieux de rencontre, évoqués précédemment, auraient alors un rôle de laboratoire, à condition que l'on s'interroge sur les modalités de ces rencontres, et sur les conditions de production des sources. Lucy K. Pick, dans une étude sur l'attitude de l'évêque de Tolède face aux juifs dans la première moitié du XIII ${ }^{\mathrm{e}}$ siècle, en pleine période de Reconquista, montrait que les débats religieux étaient surtout des mises en scène. Ils étaient voués à renforcer le sentiment d'appartenance à la communauté chrétienne des assistants, ainsi que des potentiels lecteurs de ces débats mis à l'écrit. «Personne, écrit-elle, n'avait le moindre doute sur le fait qu'il s'agissait de jouer un rôle, étroitement restreint aux besoins et aux attentes chrétiennes ${ }^{36}{ }$. La rencontre imaginée sert alors d'autant mieux la communauté imaginée qu'elle se réécrit librement, les juifs ayant également la possibilité de mettre par écrit certains débats pour un usage interne à leur communauté. Dès lors, la frontière entre rejet et échange est mince, et ce sont les jeux de mise en scène, d'écart et de rapprochement qui retiennent l'attention.

Asia, dir. Lieselotte E. Saurma-Jeltsch et Anja Eisenbeiss, Berlin, Allemagne, Deutscher Kunstverlag, 2010.

35 Pour un exemple d'un tel programme, voir Andrea Zannini, Venezia città aperta : gli stranieri e la Serenissima, XIV-XVIII sec., Venezia, Marcianum Press, coll. « Metropoli », 2009.

${ }^{36}$ Lucy K. Pick, Conflict and coexistence : Archbishop Rodrigo and the Muslims and Jews in medieval Spain, Ann Arbor, University of Michigan, coll. " History, languages and cultures of the Spanish and Portuguese worlds », 2004, p. 180-203. Citation originale : " no one was under any illusion that they were doing anything other than playing a part, tightly circumscribed by Christian needs and expectations ». 
La figure de l'autre, tout comme le concept d'altérité, n'existe pas sans être mise en situation. Le détail des traits, des vêtements, des pratiques, ou des mots qui reviennent dans les représentations médiévales de l'altérité sont alors significatifs. Lorsqu'il s'agit de décrire ce qui, au Moyen Âge, matérialise la différence entre deux personnes ou deux groupes, plusieurs critères sont invariablement évoqués.

\section{Concrétiser l'altérité, donner une direction aux échanges}

La religion intervient presque systématiquement, non sans une ambiguïté sur les limites du champ religieux. Ainsi, le terme de «sarrasin» sert facilement de synonyme à celui de barbare, sans renvoyer nécessairement à l'Islam ${ }^{37}$, tandis que celui de «grec » renvoie plus largement à un chrétien orthodoxe résident dans un Empire byzantin aux frontières floues. Il est peu probable qu'un musulman ou qu'un orthodoxe se soient reconnus dans de tels termes, qui renvoient donc à l'imaginaire culturel et géographique de celui qui les prononce. Ce dernier écarte ainsi les membres d'une autre religion de sa communauté imaginée de salut, et les place dans un espace mental qui emprunte à la géographie chrétienne. Plus que la religion, c'est la perception construite d'une religion par une autre qui est donc souvent en jeu. La langue est également un critère essentiel, puisque c'est à travers elle que les échanges s'organisent ${ }^{38}$. Il s'agit dans ce cas d'évaluer une production linguistique en contexte. La langue comme koinè sert parfois à rapprocher, comme c'est le cas de l'italien des marchands qui a servi de

${ }^{37}$ Pour une approche soucieuse des nuances chronologiques, voir John Victor Tolan, Les Sarrasins : l'islam dans l'imagination européenne au Moyen Âge, Paris, Aubier, coll. «Collection historique », 2003.

${ }^{38}$ On exclura ici le mythe du commerce silencieux. Philip Curtin avait déjà pointé la nécessité d'intermédiaires et de codes, même dans un tel commerce. Philip D. Curtin, Cross-cultural trade in world history, Cambridge, Cambridge University Press, coll. « Studies in comparative world history », 1986, p. 12. 
lingua franca jusqu'à l'aube de l'époque moderne en Méditerranée orientale $^{39}$. Au contraire d'autres langues peuvent servir de marqueur de distinction, culturel ou social. Il est intéressant de voir comment les contemporains percevaient ces formes et où ils plaçaient eux-mêmes la barrière d'une langue à l'autre ${ }^{40}$. Ainsi l'altérité peut se glisser même là où l'intercompréhension reste possible.

Trois autres critères méritent enfin d'être ajoutés, dans l'ordre de fréquence dans lequel ils sont généralement cités. Les vêtements formeraient la première marque apparente d'altérité. Plus que n'importe quel objet, ils auraient une force performative qui, dans les années 1980, avait même été qualifiée de «logique cognitive ${ }^{41} »$. Le contrôle des communautés passe donc par des normes vestimentaires strictes et contraignantes. De même, lors du passage d'un groupe à l'autre, le changement de vêtement devient un véritable topos littéraire. La pilosité peut également être déclinée comme un critère à part entière. Ainsi, le Devisement $d u$ Monde mentionne en Chine des «monstiers et abbacies qui sont si granz comme une petite cité, et avec plus de deux mille moines selonc leur coustume. Et se vestent plus honnestement que les

39 Jocelyne Dakhlia, Lingua Franca, histoire d'une langue métisse en Méditerranée, Arles, Actes-Sud, coll. «Bleu », 2008. Notamment le chapitre VI.

${ }^{40}$ Benoît Grévin, Le Parchemin des cieux, op. cit., p. 275 sq.

41 «The conventions on clothing, however, were in a different category of cognitive logic. The connection between the sensory process of assimilating information and the symbolic meaning of dress was much stronger than in the case of food habits. If an individual changed his clothing, he automatically changed his social identity and became another person. », K. N Chaudhuri, Trade and civilisation in the Indian Ocean: an economic history from the rise of Islam to 1750, New York, Cambridge University Press, 1985, p. 156 («Cependant les conventions concernant les vêtements relevaient d'une catégorie différente de la logique cognitive. La connexion entre le processus sensoriel d'assimilation des informations et la signification symbolique du costume était bien plus forte que celle concernant les habitudes alimentaires. Un individu changeant de vêtement changeait automatiquement d'identité sociale et devenait une autre personne. », nous traduisons). 
autres genz; car il portent le chief et la barbe rese ${ }^{42} »$. On voit là une identification à la fois physique et morale à des pratiques d'ascèse facilement identifiables pour un lecteur familier du monachisme latin. Au-delà de la différence culturelle, les distinctions sociales se rejouent dans ces caractéristiques. Enfin, la nourriture est elle aussi une pratique distinctive, que ce soit par des interdits alimentaires, des préférences sociales, ou de simples différences de ressource. Bertrandon de la Brocquière, lors du voyage qui le mène de la Terre Sainte jusqu'à Constantinople au début $\mathrm{du} \mathrm{XV}^{\mathrm{e}}$ siècle, rapporte ainsi les pratiques alimentaires des Turcs d'Anatolie :

Le pain que on y mengue en aulcune marche est estrange à qui ne l'a accoustumé, car il est tresmol et samble qu'il ne soit point à moitié cuit, selon nostre coustume. Ils menguent de la char crue sechiée au soleil. Se une de leurs bestes, camel ou cheval, est en dangier de mort qu'ilz n'y sachent remede, incontinent lui coppent la gorge et puis ilz l'escorchent et menguent, mais non pas sans le cuire, ains le cuisent ung pou ${ }^{43}$.

Dans ce balancement incertain entre cru et cuit, le voyageur du début $\mathrm{du} X v^{\mathrm{e}}$ siècle cherche à expliquer à ses lecteurs de nouveaux aliments en fonction des concepts qu'ils connaissent et non à exoticiser les pratiques qu'il rencontre. L'autre apparaît comme une figure complexe dont sont toujours retenus préférentiellement certains traits voués à insister ou non sur l'altérité. Pas de rencontre avec l'autre sans mise en scène, ou du moins sans contexte, pas d'altérité culturelle sans une grille de lecture préalable.

\footnotetext{
${ }^{42}$ Marco Polo, Le Livre de Marco Polo, Paris, Firmin Didot, 1865, p. 233. Sur la culture de Marco Polo, voir John Larner, Marco Polo and the discovery of the world, New Haven, Yale University Press, 1999.

43 Le Voyage d'outremer de Bertrandon de la Broquiere, éd. Charles Henri Auguste Schefer, Paris, E. Leroux, 1892, p. 97.
} 
Les textes, que leur visée soit davantage esthétique - littéraire - ou bien informative - encyclopédique et scientifique - illustrent avec une acuité particulière toutes les médiations et mises en scène qui configurent la rencontre de l'altérité culturelle. Le gauchissement, volontaire ou involontaire, et son corollaire paradoxal, l'assimilation au semblable, restent les deux axes sur lesquels se déploie l'écriture de l'altérité quelle qu'elle soit: antiquité païenne, espace byzantin, orient, peuples de l'espace germanique ou scandinave, voire encore extrême orient. Les guerriers homériques du Roman de Troie n'ont ainsi de grec que le nom (v. 5171-5176 ${ }^{44}$ ) tant les canons esthétiques et les caractérisations sociales sont celles de l'Occident latin. L'assimilation peut paraître relativement anodine dans des textes de fiction comme les romans antiques, elle l'est moins en revanche dans cette littérature engagée et partisane que sont les chroniques et récits de croisades, où l'ethnocentrisme résulte d'un projet clair ${ }^{45}$. À l'inverse, les textes peuvent accentuer la différence culturelle à travers la merveille et son pendant négatif, la monstruosité. La tératologie ${ }^{46}$ fait ainsi figure de ressort classique de l'écriture de la culture autre et constitue un indice sûr du seuil d'altérité. Quand l'altérité culturelle ne se dit pas au moyen du monstrueux, c'est la merveille, fascinante et inquiétante, qui peut lui suppléer en fournissant semblablement le prétexte d'une description

44 Benoît de Sainte Maure, Le Roman de Troie, Emmanuèle Baumgartner et Françoise Vielliard, Paris, Librairie Générale Française, coll. «Lettres Gothiques », 1998, p. 192 : «Patroclus rot le cors mout gent /E mout fu de grant escïent. /Blans fu e blois e dreiz e granz /E chevaliers mout avenanz. /Les oilz ot vairs, n'ot pas grant ire /Biaus fut mout, ce puet hon bien dire ».

${ }^{45}$ Sur cette tension entre représentation mimétique et assimilation radicale du fait de mobiles culturels et religieux dans des textes littéraires, on pourra consulter la mise au point nuancée et à la théorisation rigoureuse de Catherine Croizy-Naquet, «Y a-til une représentation de l'Orient dans la Chronique d'Ernoul et de Bernard le trésorier? », Cahiers de recherches médiévales, $\mathrm{n}^{\mathrm{0}} 8,2001$, consulté le 06 juillet 2016. URL : http://crm.revues.org/412 ; DOI : 10.4000/crm.412.

${ }^{46}$ Claude-Claire Kappler, Monstres, démons et merveilles à la fin du Moyen Âge, Paris, Payot et Rivages, « Bibliothèque historique Payot », 1999. 
impuissante à épuiser la différence. Ainsi, les automates carthaginois de Didon dans le Roman d'Enéas (v. 444-484) sont autant de signes d'une maîtrise technologique qui est l'apanage d'une autre culture, en l'occurrence celle de l'Orient et non de l'Antiquité. La fascination pour l'altérité n'offre pas seulement un prétexte à des ekphrasis dans les textes littéraires : elle est en réalité un détour du discours pour se penser dans sa singularité culturelle. La translatio studii des romans antiques ou les héritiers monstrueux de Mélusine qui partent à l'assaut de l'Orient ${ }^{47}$ sont des fictions qui disent le politique à travers une logique généalogique. L'Orient, terre par excellence des mirabilia, semble donc jouir d'une position particulière dans la définition de l'altérité au Moyen Âge.

\section{L'Orient : horizon du Moyen Âge occidental ?}

L'Orient fait figure d'horizon incontournable pour le Moyen Âge, ce qui tend à établir une hiérarchie entre les différentes altérités culturelles. Or, qu'est-ce que l'Orient pour les récits de pèlerinage, les chansons de geste, la poésie et le roman médiéval ? C'est aussi bien l'Espagne andalouse que Jérusalem : ces espaces, à la différence de la Scandinavie, font l'objet d'un traitement spécifique. L'Orient reste en effet, dans la mise en scène qu'en font les textes, presque toujours autre : fascinant et menaçant. À cette aune, peut-on reprendre en littérature les analyses d'Edward Saïd développées pour la période moderne ? Il nous semble que oui, dès lors que l'on se borne à la dimension symbolique qu'élaborent les textes : en eux se joue peut-être déjà une polarisation culturelle spécifique, une «orientalisation» de certains espaces. En

\footnotetext{
47 Pour une reprise synthétique de l'abondante bibliographie disponible sur la question, on pourra se reporter à l'ouvrage de Francine Mora-Lebrun, "Mettre en romanz.", Les Romans d'Antiquité du XII siècle et leur postérité, Paris, Honoré Champion, 2008, chap. II, « La translatio imperii une réflexion historique et politique sous-jacente », p. 223-287.
} 
somme, les textes du Moyen Âge sont peut-être un des jalons d'une « pré-histoire » de l'Orient.

L'application des théories d'Edward Saïd à l'époque médiévale en histoire a déjà fait couler beaucoup d'encre : comme le faisait remarquer Lucy K. Pick en 1999, parmi les trois formes d'orientalisme identifiées par E. Saïd, seul l'orientalisme académique trouverait ses racines au Moyen $\hat{A g e}^{48}$. Il est en effet complexe de lier connaissance du Proche et Moyen-Orient et impérialisme avant la fin de l'époque moderne ${ }^{49}$. Lucy K. Pick invitait donc à considérer l'orientalisme comme un continuum : pour ne pas en essentialiser les aspects modernes, il faudrait repenser ses liens avec les écrits religieux médiévaux portant sur l'Orient. En guise d'illustration, on évoquera l'ouvrage de John Tolan intitulé Le Saint chez le Sultan : la rencontre de Saint François d'Assise et de l'Islam. Estimant qu'il est impossible de savoir ce qui s'est réellement dit en 1219, alors que les croisés échouaient à prendre Damiette, entre François et le sultan Malik al-Kâmil, John Tolan opte pour un parcours historique de plus longue haleine : une analyse de la manière dont cet événement a été lu depuis le XIII ${ }^{\mathrm{e}}$ siècle jusqu'aux premières années du XXI ${ }^{\mathrm{e}}$ siècle selon des contextes politiques changeants ${ }^{50}$. Après deux siècles de lectures marquées par l'hagiographie, la figure du sultan se transforma $d u X V^{e}$ au $\mathrm{XVII}^{\mathrm{e}}$ siècle, pour devenir une image de la violence et de la barbarie, en réponse à la montée de la menace ottomane. Voltaire, quant à lui, voyait dans Saint François un fou entêté à se présenter devant un sultan tolérant.

\footnotetext{
${ }^{48}$ Lucy K. Pick, «Edward Said, Orientalism and the Middle Ages », Medieval Encounters, 1999, vol. 5, n 3, p. 265-271.

${ }^{49}$ Pour deux synthèses plus récentes, voir Jeffrey Jerome Cohen, The Postcolonial Middle Ages, New York, St. Martin's Press, 2000, et Kim M. Phillips, Before Orientalism: Asian peoples and cultures in European travel writing, 1245-1510, Philadephia, University of Pennsylvania Press, 2014.

${ }^{50}$ John Victor Tolan, Le Saint chez le sultan. La rencontre de François d'Assise et de l'islam : huit siècles d'interprétation, Paris, Éditions du Seuil, 2007.
} 
Finalement, c'est au XIX ${ }^{\mathrm{e}}$ siècle qu'apparaît l'image du saint porteur des valeurs civilisatrices, alors même que les Franciscains s'emploient à légitimer leur présence à Jérusalem. Comme souvent pour les médiévistes, les faits mêmes des rencontres sont perdus, et lorsqu'ils subsistent il est rare d'entendre les deux partis à part égale. Ces manques forcent à envisager aussi la mise en scène, et les rôles que l'on pouvait accepter ou exiger de l'autre pour donner de la cohérence à une culture.

Les textes proposés suivent ce souci de contextualisation, et font alterner altérité locale, rapport entre Occident et Orient, et confrontation au merveilleux, comme autant d'étapes d'un parcours qui menait les hommes du Moyen Âge à la rencontre de l'autre.

Adrien Carbonnet et Jonathan Bloch se penchent donc sur la complexité réelle des rapports entre les différentes populations du Royaume de France, ainsi qu'avec les Flamands, dans un contexte de guerre et de début de construction de l'identité nationale. Jean-David Richaud analyse quant à lui une situation interne à l'Orient : les difficiles rapports entre population arabe et Turcs seldjoukides. Trois communications s'attachent ensuite à jeter différents éclairages sur les rapports entre Occident et Orient : Cristina Dusio et Marco Robecchi étudient la représentation littéraire d'un lieu mythifié : la tour Baudaire ; Marco Robecchi se concentre ensuite sur la frontière entre stéréotype et expérience individuelle dans l'œuvre de Riccold de Montecroix, tandis que Florian Besson examine les mots et les cadeaux qui circulent... ou non dans l'Orient des croisades. Enfin Camille Carnaille étend le propos à la question de la subjectivité, en examinant la place que les textes merveilleux font aux émotions. La lecture se propose donc comme un parcours allant du proche au lointain, mais faite aussi d'aller-retour entre intériorité et extériorité, entre soi et les autres. 